\title{
Consortia Building: A Handshake and a Smile, Island Style
}

In the evaluation of consortia and what constitutes these entities the discussion runs the gamut. From small, loosely knit groups who are interested in cooperation for the sake of improving services to large membershipdriven organizations addressing multiple interests, all recognize the benefits of partnerships.

The Federated States of Micronesia are located in the western Pacific Ocean and cover 3.2 million square miles. Throughout this scattering of small islands exists an enthusiastic library community of staff and users that have changed the outlook of libraries since 1991. Motivated by the collaborative efforts of this group, a project has unfolded over the past year that will further enhance library services through staff training and education while utilizing innovative technology. In assessing the library needs of the region this group crafted the document "The Federated States of Micronesia Library Services Plan, 1999-2003," which coalesces the concepts, goals, and priorities put forward by a broad-based contingency of librarians. The compilation of the plan and its implementation demonstrate an understanding of the issues and exhibit the ingenuity, creativity, and willingness to solve problems on a grand scale addressing the needs of all libraries in this wast Pacific region.

$\mathrm{T}$ The basic philosophy inherent in librarianship is the concept of sharing. The dissemination of information through material exchange and interlibrary communication has enriched societies for centuries. There are few institutions other than libraries that are better equipped or suited for such cooperation and collaborative endeavors. With service as the lifeblood that runs through its inky veins, the library has the potential to be the driving force in any community toward partnerships that afford mutual benefit for all.

The examination of the literature exposes a wide range of perceptions as to the definition of what is a consortium. The term "consortia" conjures up impressions that span the spectrum from highly organized, membership-driven groups to loosely knit cadres focusing on improving services to their patrons however they can make it happen. In Kopp's paper "Library Consortia and

Patricia J. Cutright (cutright@eou.edu) is Library Director of the Pierce Library at Eastern Oregon University.
Information Technology: The Past, the Present, the Promise" he presents information from a study conducted by Ruth Patrick on academic library consortia. In that study she identified four general types of consortia:

- Large consortia concerned primarily with computerized large-scale technical processing;

- Small consortia concerned with user services and everyday problems;

- Limited-purpose consortia cooperating with respect to limited special subject areas;

- Limited-purpose consortia concerned primarily with interlibrary loan or reference; and network operations. 1

With this distinction in mind, this paper will focus on the second category typifying a small, less structured organization.

While on a visiting assistantship in the Federated States of Micronesia (FSM), I worked with a partnership of libraries that believe in order for cooperation to succeed, results for the patron must be the goal-not equity between libraries or some magical balance between resources lent by one library and resources received from another library. ${ }^{2}$ Unified efforts to provide service to the patron is the key.

The libraries on a small, remote island situated in the western Pacific Ocean exhibit this grassroots effort that defines the true meaning of consortia-demonstrating collaboration, cooperation, and partnerships. It is a multitype library cooperative that not only encompasses interaction among libraries but also between agencies as well as governments. The librarians on the island of Pohnpei, Micronesia, and all the islands throughout the Federated States of Micronesia have embraced this consortial attitude while achieving much through these collaborative efforts:

- The joint work done on crafting the Library Services Plan, 1999-2003 for the libraries throughout the Federated States of Micronesia

- Initiating successful grant-writing efforts which target national goals and priorities

- Implementing a collaborative library automation project which is designed to evolve into a national union catalog

- The implementation of a viable resource-sharing and document delivery service for the nation

\section{Background and Socioeconomic Overview}

Micronesia, a name meaning "tiny islands," comprises some 2,200 volcanic and coral islands spread throughout 
3.2 million square miles of Pacific Ocean. Lying west of Hawaii, east of the Philippines, south of Japan and north of Australia, the total land mass of all these tropical islands is fewer than 1,200 square miles with a population base estimated at no more than $111,500.3$ A locationunique region, but nonetheless still plagued with all the problems associated with any geographically remote, economically depressed area found anywhere in the United States or elsewhere in the world.

The Federated States of Micronesia is a small-island, developing nation that is aligned with the United States through a Compact of Free Association, making it eligible for many U.S. federal programs. The economic base is centered around fisheries and marine-related industries, tourism, agriculture, and small-scale manufacturing. The average per capita income in 1996 was $\$ 1,657$ for the four states of the FSM: Kosrae, Pohnpei, Yap, and Chuuk. Thirteen major languages exist in the country, with English as the primary second language. The 607 different islands, atolls, and islets dot an immense expanse of ocean; this geographic condition presents challenges in implementing and enhancing library services and technology. ${ }^{4}$

Despite the extreme geographic and economic conditions, the College of Micronesia-FSM National campus in collaboration with the librarians throughout the states have been successful in implementing nationwide projects. These endeavors have resulted in technical infrastructure and the foundation for information technology instruction supported through awards from the U.S. Department of Education, the Title III program, and the National Science Foundation.

\section{Collaboration: Building Bridges that Cross the Oceans}

The libraries in Micronesia have shown an ongoing commitment to librarianship and cooperation since the establishment of the Pacific Islands Association of Libraries and Archives (PIALA) in 1991. The organization is a Micronesia-based regional association committed to fostering awareness and encouraging cooperation and resource sharing among libraries, archives, museums, and related institutions.

PIALA was formed to address the needs of Pacific Islands librarians and archivists, with a special focus on Micronesia; it is responsible for the common-thread cohesiveness shared by the librarians over the past eight years. The organization has grown to become an effective champion of the needs of libraries and librarians in the Pacific region. ${ }^{5}$

When PIALA was established, the most pressing areas of concern within the region were development of resource-sharing tools and networks among the libraries, archives, museums, and related institutions of the Pacific Islands. The development of continuing education programs and the promotion of technology and telecommunications applications throughout the region were areas targeted for attention. Those concerns have changed little since the group's inception.

Building upon that original premise, in January 1999 a group of interested parties from throughout the Federated States of Micronesia met to draft a document they envisioned would lay the groundwork for library planning over the next five years. This strategic plan encompasses all library activity-services, staffing, and the impact technology will have on libraries in the region.

The document, "The Federated States of Micronesia Library Services Plan, 1999-2003," coalesces the concepts, goals, and priorities put forward by a broad-based contingent. In this meeting, the group addressed basic issues of library and museum service, barriers and solutions to improve service delivery, and additional funding and training resources for libraries and museums. ${ }^{6}$ The compilation of the plan crafted at the gathering demonstrated a thorough understanding of the issues that face the librarians of the vast region. It exhibits the ingenuity, creativity, and willingness to problem-solve on a grand scale in a way that addresses the needs of all libraries in the Pacific region.

The goals set forward by the writing session group illustrate the concerns impacting library populations throughout the FSM. The FSM has now established six major goals to carry out its responsibilities and the need for overall improvement in and delivery of library services:

1. Establish or enhance electronic linkages between and among libraries, archives, and museums in the FSM.

2. Enhance basic services delivery and promote improvement of infrastructure and facilities.

3. Develop and deliver training programs for library staff and users of the libraries.

4. Promote public education and awareness of libraries as information systems and sources for lifelong learning.

5. Develop local and nationwide partnerships for the establishment and enhancement of libraries, museums, and archives.

6. Improve quality of information access for all segments of the FSM population and extend access to information to underserved segments of the population.

\section{Priorities}

The following are general priorities for the FSM Library Services Plan. The priorities represent needs for overall improvement of the libraries, museums, and archives. The priorities are based on the fact that currently libraries, museums, and archives development is in its infancy in 
the FSM. Specific priorities will change from year to year as programs are developed.

1. Establishment of new libraries and enhancement of existing library facilities to increase accessibility of all FSM citizens to library resources and services. Outer islands and remote areas generally have no access to libraries or information sources. New facilities or mechanisms need to be established to provide access to information resources for the public. Existing public and school library facilities often lack adequate staffing, climate control, and electrical connections needed to meet the needs of the community. Existing public and school libraries also need to improve their facilities and services delivery to meet the needs of disabled individuals and other special populations.

2. Provide training and professional development for library operation and use of new information technologies. A survey held during the writing session indicated that public and school library staff do not currently possess the skills needed to effectively provide assistance in the use of new information technologies. Well-designed training programs with mechanisms for follow-up technical assistance and support need to be developed and implemented.

3 . Promote collaboration and cooperation among libraries, museums, and archives for sharing of holdings and technical ability. Limited holdings, financial capacity, and human resources are major barriers to improving library services. Collaboration and cooperation are needed among libraries, museums, and archives to maximize scarce resources.

4. Develop recommended standards and guidelines for library services in the FSM. The ability to share resources and information could be significantly increased by development and implementation of recommended standards and guidelines for library services. Standardization could assist with sharing of holdings and holdings information, increase availability of technical assistance, and provide guidance as new libraries and library services are set up.

5. Increase access to electronic information sources. Existing public and school libraries have limited or no access to electronic linkages including basic services such as e-mail and connections to the Internet. The priority need is to establish basic electronic linkages for all libraries, followed by extending access to electronic information to all users. ${ }^{7}$

\section{Shifting into Action}

With the drafting of this five-year plan, the librarians stated emphatically the need and desire to move ahead with haste and determination. As the plan was conceptualized and documented, a small cadre of librarians from the College of Micronesia-FSM National campus, the public library, and high school library crafted two successful grant proposals which addressed:

- a cooperative library automation project which is designed to evolve into a national union catalog (goal 1; priorities 3, 5);

- the installation of Internet services that would link the College of Micronesia-FSM campuses, the public library, and high school library (goals 1, 2, 6; priorities $1,2,3,5$ );

- the development and delivery of training programs for library staff and users of the libraries (goals $3,4,6$; priority 2); and

- the implementation of a viable resource-sharing and document delivery service for the nation (goal $1,2,5,6$; priorities $3,4,5$ ).

Over the past year the awarding of grant funds has shifted the library community into high gear with the design and implementation of project activities that will fulfill the targeted needs.

\section{The Automation Project and Internet Connectivity}

A collaborative request submitted by the Bailey Olter High School (BOHS) library and the Pohnpei Public Library provided the funding necessary to computerize the manual card catalog system at BOHS and upgrade the dated automated library system at Pohnpei Public Library.

Since the College of Micronesia-FSM campuses are automated, it was important for the high school library and the public library to install like systems to achieve a networkable automated system, facilitating the development of a union catalog for all the libraries' holdings. This migration to an automated system promoted cooperation and resource sharing for the island libraries-opening a wealth of information for all island residents.

The project entailed purchasing a turnkey cataloging and circulation system that will facilitate the cataloging and processing of new acquisitions for each library as well as the conversion of approximately five thousand volumes of material already owned by the public and high school libraries. Through Internet connectivity, which was integral to the project, the system would also serve as public access to the many holdings of the libraries for students, faculty, and town patrons through a union catalog to be established in the future.

The development and delivery of training programs for library staff and users is linked to the implementation of a viable resource-sharing and document delivery service for the nation.

Stated earlier, the librarians of the Federated States of Micronesia accepted the challenge facing them in ramp- 
ing up for the twenty-first century. Their prior experience laid the groundwork necessary to implement the training programs necessary to bring the library community the knowledge and skills needed.

A survey administered during the writing session indicated that few public and school librarians have significant training in or use of electronic linkages or information technologies, nor are they actively using such technologies at present. Of the fourteen public and school librarians in the four states of Micronesia, none hold a master's degree from an accredited library school or Library Media Specialist certification. An exception is the library staff at the COM-FSM National campus, where two-thirds of the librarians hold professional credentials.

Significant effort is needed on a sustained basis for effective training in the understanding and use of information systems throughout the nation. Where training has occurred, it has often been of an infrequent, short variety with little support for ensuring implementation at the work site. Additionally, often there are no formal systems for getting answers to questions when problems do arise.

In addressing the information needs for this population it is apparent that education is the key component for continued improvement of library services. This concern is evident in a paper by Daniel Barron, where it is stated that only 54 percent of librarians and 19 percent of staff in libraries serving communities considered to be rural (i.e., 25,000 people or fewer) have an ALA-MLS. 8 And Dowlin proposes even more perplexing questions, "How can a staff with such an educational deficit be expected to accomplish all that will be demanded to enable their libraries to go beyond being a warehouse of popular reading materials? How can we expect them to change from pointers and retrievers to organizers and facilitators?"9

Micronesia is no different than any other state or country in wanting its population to have access to qualified staff, current resources, and services. It recognizes the libraries are inadequately staffed and many others have staff who are seriously undereducated to meet the expanded information needs of the people in their communities. If these libraries are to seize the opportunities suggested by the developing positive view, develop services to support this view, and market such a view to a wider range of citizens in their communities they must invest in the intellectual capital of their staffs.

In order to carry out this charge, the following activities were designed to address the educational and training needs of the librarians in the FSM. As outlined in a recently funded Institute of Museums and Library Services (IMLS) National Leadership grant, preparation has begun with the following activities, which will address the staffing and technology concerns described in FSM libraries:
1. Recruit and hire an outreach services librarian to survey training needs, coordinate and plan training, and deliver or arrange for needed training.

2. Develop a skills profile for all library, museum, and archival staff positions.

3. Identify training contact or coordinator for each state.

4. Develop and provide periodic updates to operational manuals for school and public libraries, museums, and archives.

5. Recruit local students and assist them in seeking out scholarships for professional training off island.

6. Design and implement programs to provide continuous training and on-site support in new technological developments and information systems (provided on-site and virtually).

7. Establish a Summer Training Institute offering training based on needs as determined by the Outreach Services Librarian in collaboration with state coordinators and recruiting on- and off-island expertise as instructors.

8. Design and develop programs for orientation and training of users of information systems (provided on-site and virtually).

9. Develop and implement a "train the trainer" program, which will have representation from all four states, that will ensure continuity and sustainability of the project for the years to come. ${ }^{10}$

The primary requisite to initiating this project is the recruitment and hiring of the outreach services librarian who will then begin the activities as listed. A beginning cadre of librarians gleaned from the summer institute will become the trainers of the future, perpetuating a learning environment enhanced with advanced technology.

Breakthroughs in distance education, aided with advances in telecommunications, will significantly impact this project. On-site training will be imperative for the initial cadre of summer institute attendees to provide sound teaching skills and a firm understanding of the material at hand. Follow-up training will be presented on each island by the trainer either on location or virtually with available technology. Products such as Web Course in a Box, WebCT, or Nicenet will be analyzed for appropriate utilization as teaching tools. These products will take advantage of newly established Internet connections on each island and, more importantly, will provide the interactive element that distinguishes this learning methodology from the "talking head" or traditional correspondence course approach. A Web site designed for this project will provide valuable information and connectivity for not only the Pacific library community but anyone worldwide who may be interested in innovative methods of serving remote populations.

Using computer conferencing and virtual communities technology, a video conferencing system such as $8 \times 8$ 
Technologies will be used, which will allow face-to-face interaction with trainer and student in an intra-island situation (interisland telephone rates are too expensive for regular use as a teaching tool).

To enhance the learning experience and information retrieval component for these librarians and the population they serve, the project also incorporates implementation of a viable resource-sharing, document delivery system capitalizing on a shared union catalog and using a service such as Research Library Group's Ariel product. With library budgets reflecting the critical economic climate of the nation, it becomes even more crucial for collaborative collection development and resource sharing to satisfy the needs of the library user.

To maintain cost-effective communication and build a sense of community among the librarians, the messaging software ICQ has been installed on all participant hardware and utilized for group meetings, question and answer, and general correspondence. Since ICQ operates as part of the Internet, this package allows low-cost communication with maximum benefit in connecting the group. This technology will also be used as the primary mechanism for communication with an outside advisor who will provide expertise in the area of outreach services for rural populations.

The realm of outreach services in libraries has always presented unique challenges that can now benefit greatly from current and emerging technologies. The definition of "outreach" is truly a matter of perspective, with the more traditional sense relating to a specific library servicing its own user or patron. But current practice regards "outreach" as a mere extension of services to all users whether they be a registered patron or colleague or peer.

Micronesia is a country where the proverbial phrase "the haves and the have-nots" is amplified. The recent (and ongoing) installation of Internet services in the region has made possible many basic changes, but there still exists the reality that some of the sites for services proposed have nothing more than a common analog line and rudimentary services. As an example of the realities that exist, only 38 percent of the approximately 180 public schools in the FSM have access to reliable sources of electricity. Another challenge for these libraries is the climate and environment, which has a significant impact on library facilities, equipment, and holdings. The FSM lies in the tropics, with temperatures ranging daily from 85 to 95 degrees with humidity normally 85 percent or higher. ${ }^{11}$ The high salt content in the ocean air wreaks havoc upon electrical equipment, and the favorable environs inside a library often entice every thing from termites in the wooden bookcases to nesting ants in keyboards. From these examples it is apparent that the problems that trouble these libraries are not going to be solved with the magic bullet of technology. This reality constitutes the need for varying strategies and different aproaches to address the training requirements of the library staff.

\section{Summary}

The FSM library group, in particular the Pohnpeian librarians, have accomplished much in the past year. The motivating factor for the flurry of activity that enveloped the libraries on Pohnpei was spurred by the collaborative writing session in January 1999. A week-long "meeting of the minds" from libraries throughout Micronesia produced the blueprint that will map the future of libraries and library service for years to come. These librarians stated their primary issues in delivering library services and came to a consensus on activities needed to address the issues. The "Federated States of Micronesia Library Services Plan, 1999-2003" was crafted as a working document, a strategic plan for improving library services in the Pacific region, and a commitment to achievement through collaboration.

While in Micronesia I observed the impact that the unification of ideas can have on the citizens of a community. In my fourteen-year tenure at Eastern Oregon University I have been exposed to the benefits of "consortium attitude" that come from cooperation and partnerships. Time and again the university demonstrates the positive effects of what is referred to as "politics of entanglement." Shepard describes the overriding philosophy that has been the recipe for success:

The politics are really quite simple. We maintain an
intricate pattern of relationships, any one of which
might seem inconsequential. Yet there is strength in
the whole that is largely unaffected if a single relation-
ship wanes. Rather than mindlessly guarding turf, we
seek to involve larger outside entities and in the
ensnaring, to turn potential competitors into helpful
partners.12

Just as Eastern Oregon University has discovered, the libraries of the Federated States of Micronesia are learning the merits of entanglement.

\section{References and Notes}

1. James J. Kopp, "Library Consortia and Information Technology: The Past, the Present, the Promise," Information Technology and Libraries 17 (Mar. 1998): 7-12.

2. Jan Ison, "Rural Public Libraries in Multi-type Library Cooperatives," Library Trends 44 (Summer 1995): 29-52

3. Pacific Islands Association of Libraries and Archives, www.uog.edu/rfk/piala.html, accessed June 6, 2000.

4. Division of Education, Department of Health, Education and Social Affairs, Federated States of Micronesia, "Federated 
States of Micronesia, Library Services Plan 1999-2003" (March 3, 1999): 2

5. Pacific 1slands Association of Libraries and Archives, www.uog.edu/rfk/piala.html, accessed June 6, 2000.

6. Division of Education and others, "Library Services Plan," 4.

7. Ibid, 6 .

8. Daniel D. Barron, "Staffing Rural Pubic Libraries: The Need to Invest in Intellectual Capital," Library Trends 44 (Summer 1995): 77-88.
9. K. E. Dowlin, "The Neographic Library: A 30-Year Perspective on Public Libraries," in Libraries and the Future: Essays on the Library in the Twenty-First Century, F. W. Lancaster, ed. (New York: Haworth Pr., 1993).

10. Patricia J. Cutright and Jean Thoulag, College of Micronesia-FSM National campus, "Institute of Museums and Library Services, National Leadership Grant" (Mar. 19, 1999).

11. Division of Education and others, "Library Services Plan," 2.

12. W. Bruce Shepard, "Spinning Interinstitutional Webs," AAHE Bulletin 49 (Feb. 1997): 3-6.

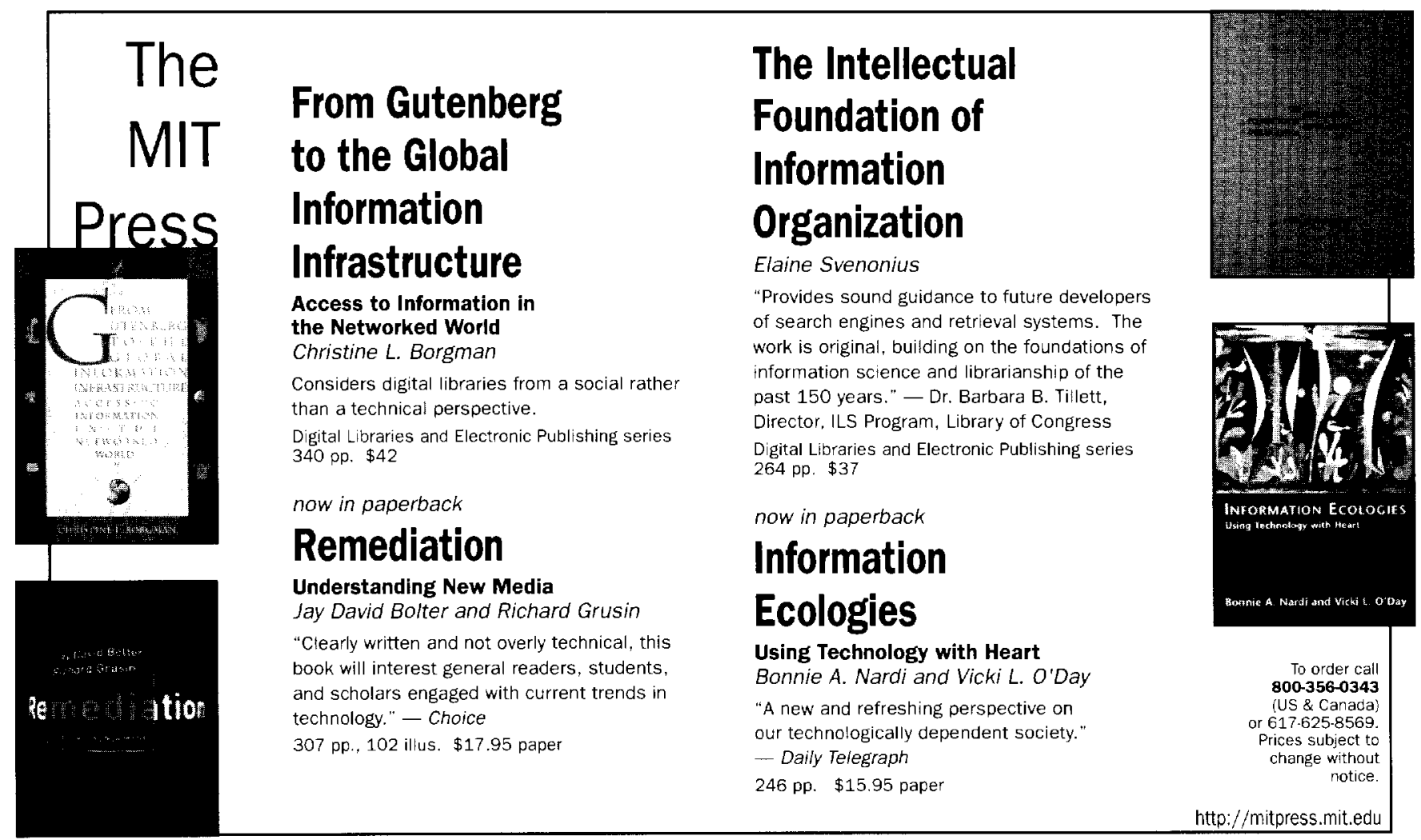

